\title{
Innovative earthing systems for electric power substations using conductive nanoparticles
}

\author{
Ahmed Thabet ${ }^{1}$, Youssef Mobarak ${ }^{2}$ \\ ${ }^{1}$ Electrical Engineering Department, College of Engineering, Qassim University, Buraydah, Kingdom of Saudi Arabia \\ ${ }^{1,2}$ Nanotechnology Research Center, Faculty of Energy Engineering, Aswan University, Aswan, Egypt
}

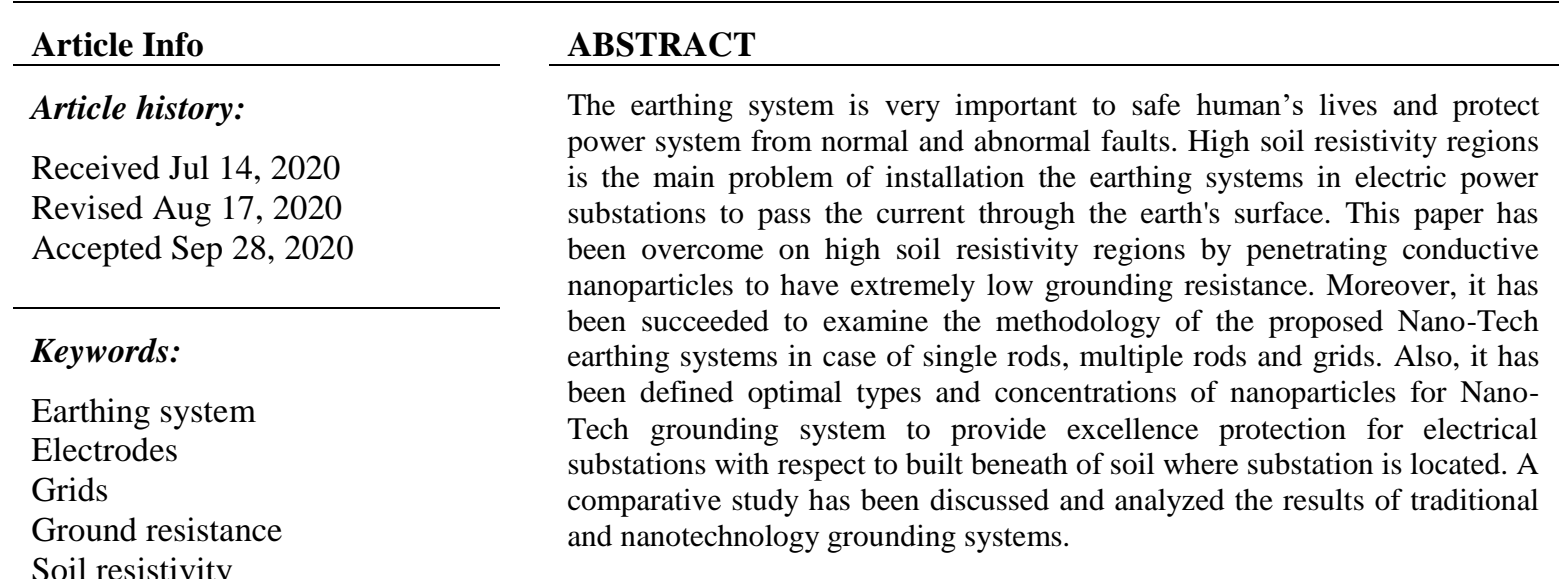

This is an open access article under the CC BY-SA license.

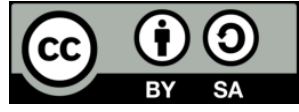

Corresponding Author:

Ahmed Thabet

Department of Electrical Engineering

Aswan University

Sahary Road, Aswan 81528, Egypt

Email: athm@aswu.edu.eg

\section{INTRODUCTION}

Every electrical equipment's, apparatus, system must be earthed or grounded to acquire a low resistance path for dissipation of excess current flow into the earth. Earthing plays a significant role in generation, transmission and distribution for safe operation of any electrical power substation. Ground shortcoming current affects human safety. Significant mishaps occur because of inappropriate earthing. Indeed, every overhead line/Substation/Generator station which is presented are at risk to injury from lightning. In power stations systems, an earthing or establishing system is hardware which interfaces parts of the electric circuit with the ground, along these lines characterizing the electric capability of the transmitters comparative with the world's conductive surface. Specifically, it influences the extent and appropriation of short current out flows through the system, and the impacts it makes on hardware and individuals in the vicinity of the circuit.

The grounding system drive the ground fault current efficiently to the earth, and to protect the people within and in the surroundings of the substation. The main objective of earthing systems is carrying and dissipation the electrical currents that are produced during fault conditions into the ground, in order to ensure that a worker in the vicinity of the grounded installation is not exposed to a critical electrical shock and to ensure the proper upper limits for the step and the touch voltages have been set by international standards. Due to increasing number and complexity of AC substation, more important needs for both safety and accurate design procedures for the grounding systems. In fact, soil resistivity data is the key factor in 
designing a good grounding system because of the soil conducts electrical current to earth. The resistivity of soil varies widely throughout the world and changes dramatically within small areas.

Many theoretical methods have been discussed the calculation the earthing resistance and earth surface potentials of variant electric substation earthing systems, i.e., starting from a grid consists of one mesh or rod to a final design consisting of many regular meshes or rods [1, 2]. In recent years, as the shortage of fossil energy, distributed generation becomes the development trend of new design of earthing systems with its specialties of economy and environmental protection. and energy storage [3-5]. In case of a prospective fault current, step voltage, touch voltages and earth potential rise are kept below a safe limit. Thus, this may occur a change in soil characteristics (moisture, $\mathrm{pH}$, and organics), corrosion, accelerated aging from lightning and earth current [6-12]. As a novel solution to these problems, nanotechnology soil has aimed to both increase soil conductivity and reduce corrosion. This paper presented the effect of nanoparticles in characterization of soil earthing system and analysis the ground resistance for new nanotechnology earthing system for reducing ground resistance then enhancing ground potential performance. Thus, it has been obvious the progressive in earthing systems of electrical power systems by using nanoparticles in variant soils; it is presented new creation based on nanoparticles technique in order to design new enhancement performance of electrical power substation.

\section{GROUNDING SYSTEM}

The reason for earthing in an electric power system is to limit, concerning the general mass of earth, the capability of current flow conductors, which are a piece of the equipment, non-current carrying metal works, accessories with the equipment, mechanical assembly and appliances connected to the system framework. It is also necessary to maintained earthing properly of all electrical installation. Thus, there are two types of the earthing systems which are using electrodes or grids systems. In this section, Nano-Tech earthing system followed after the traditional earthing system models to explain the relation between resistance and length of grounding systems and the importance of nanoparticles in Nano-Tech grounding systems. In the past, the soil was treated with salt and coal there is salt and coal to help reduce the soil resistivity that the rods or the grids are buried down, whatever, this research proposed distribution of nanoparticles in the soil has been controlled in soil resistivity then affected on grounding system resistance.

\subsection{Problem of traditional grounding systems}

Soils made up of gravel, sand or stone have the highest soil resistivity that present a big problem in installation earthing system of electrical power substations in them. Moisture content, temperature and salts also affect soil resistivity. Granite, millstone, and all rock formations found in site area and all types of rock have a high electrical resistivity-a real headache when designing/installing a high voltage and low voltage electrical earthing systems. Thus, the soil resistivity is a measure of how much the soil resists or conducts electric current. It is a critical factor in design of systems that rely on passing current through the earth's surface. The grounding electrodes provide the essential function of connecting the electrical system to the earth. The earth is considered to be at zero potential. The primary purpose of the grounding electrode is to maintain the electrical equipment at the earth potential present at the grounding electrode. In addition, the purpose of grounding grid is to serve the dual purpose of carrying currents into the earth without exceeding the operating tolerances of any protected equipment while assuring that personnel in the vicinity are not exposed to electric shock as would result from excessive step or touch potentials. Considering resistivity of soil and length and diameter of the rod following (1) show the relation between resistance and length of one rod [1, 3, 13],

$$
R=\frac{\rho}{2 \pi L}\left[\log \left(\frac{8 L}{d}\right)-1\right]
$$

In case of two rods set in series, two option are available when spacing between rods is greater than length of the rod as in (2), whatever, when spacing between rods is smaller than length of the rod as in (3):

$$
\begin{aligned}
& R=\frac{\rho}{4 \pi L}\left[\log \left(\frac{8 L}{d}\right)-1\right]+\frac{\rho}{4 \pi S}\left[1-\frac{L^{2}}{3 S^{2}}\right] \\
& R=\frac{\rho}{4 \pi L}\left[\log \left(\frac{32 L^{2}}{d S}\right)-2+\frac{S}{3 L}-\frac{S^{2}}{16 L^{2}}\right]
\end{aligned}
$$

where:

$\rho \quad:$ is the resistivity of soil, in ohm meter $(\Omega . \mathrm{m})$

$\mathrm{L} \quad$ : is the length of reinforcing rod below ground level, in meter (m) 
$\mathrm{d} \quad$ : is the diameter of the rod, in meter $(\mathrm{m})$

$\mathrm{S} \quad$ : is the spacing (distance) between two rods, in meter $(\mathrm{m})$

A typical technique for getting a low ground opposition at higher voltage substations is to utilize interconnected ground networks. A typical grid system ground rods may be connected to the grid for further reduction of the ground resistance when the upper layer of soil is of much higher resistivity than that of the soil underneath. The resistance to ground determines the maximum rise of the grounding system during a ground fault $[1,3,13]$.

The following (4) for grid resistance could be used:

$$
R=\frac{\rho}{\pi L} \ln \left(\frac{2 L}{\sqrt{d h}}\right)+\frac{\mathrm{K}_{1} \mathrm{~L}}{\sqrt{A}}-\mathrm{K}_{2}
$$

where:

L : is the total length of all conductors,

A : : is the total area of the grid,

$\mathrm{h} \quad:$ is the depth at which the grid is located d is the grid conductors' diameter,

$\rho \quad: \quad$ is the resistivity of the soil

$\mathrm{d} \quad:$ is the diameter of the grid

$\mathrm{K}_{1}$ and $\mathrm{K}_{2}$ : are factors presented graphically as functions of length-to-width ratio of the grid area

\subsection{Proposed grounding systems}

In fact, soil resistivity is the resistive parameter in the grounding system for current flow to earth. Low ground obstruction is prefered or even require. If the soil has high resistivity, and the grounding system is not sufficiently arranged to power system stability, the dissipation of the electrical current running through the power system will be a result in a higher voltage on the grounding system. In addition, this has suggestions in certain application, for example, higher touch or step possibilities, or in more extraordinary cases disappointment of dependable activity of over-current or over voltage devices. According to the properties of many conventional materials that have been changed when formed or mixed with nanoparticles, the proposed Nano-Tech earthing system have been designed how to use nanoparticles distribution for changing properties of soil. Therefore, the nanometric soil resistivity has been droppd forcing the fault current to go with the earthing path, causing the efficiency and the reliability to increase and reduce the hazards of electric shocks. The (1-4) are used as the same in the new earthing system but the only difference is changing in soil resistivity $(\rho)$ to be effective resistivity $\left(\rho_{\text {eff }}\right)$ [14-20]. Effective resistivity presents the combination resistivity of nanoparticles and soil resistivities. The new conversion parameters of grounding system is being as (5) and (6):

$$
\begin{aligned}
& \sigma_{e f f}=(1-q) \sigma_{\text {soil }}+q \sigma_{\text {nanoparticles }} \\
& \rho_{\text {eff }}=\frac{1}{\sigma_{\text {eff }}}
\end{aligned}
$$

where:

$\sigma_{e f f} \quad$ is the effective conductivity, in siemens per meter $(\mathrm{S} / \mathrm{m})$

$\rho_{\text {eff }} \quad$ is the effective resistivity, in ohm meter $(\Omega . \mathrm{m})$

As shown in Figure 1, Nano-Tech earthing systems for electrical power substations has been explained the distribution of nanoparticles inside the soil medium of electrodes grounding systems and grids grounding systems respectively. In case of Electrodes nanotechnology grounding system the calculation of ground resistance is being as (7-9).

$$
\begin{aligned}
& R=\frac{\rho_{\text {eff }}}{2 \pi L}\left[\log \left(\frac{8 L}{d}\right)-1\right] \\
& R=\frac{\rho_{\text {eff }}}{4 \pi L}\left[\log \left(\frac{8 L}{d}\right)-1\right]+\frac{\rho_{\text {eff }}}{4 \pi S}\left[1-\frac{L^{2}}{3 S^{2}}\right], \text { for } \mathrm{S}>\mathrm{L} \\
& R=\frac{\rho_{\text {eff }}}{4 \pi L}\left[\log \left(\frac{32 L^{2}}{d S}\right)-2+\frac{S}{3 L}-\frac{S^{2}}{16 L^{2}}\right], \text { for } \mathrm{S}<\mathrm{L}
\end{aligned}
$$

whatever, the calculation of ground resistance of grids nanotechnology grounding system is being as (10).

$$
R=\frac{\rho_{\text {eff }}}{\pi L} \ln \left(\frac{2 L}{\sqrt{d h}}\right)+\frac{\mathrm{K}_{1} \mathrm{~L}}{\sqrt{A}}-\mathrm{K}_{2}
$$




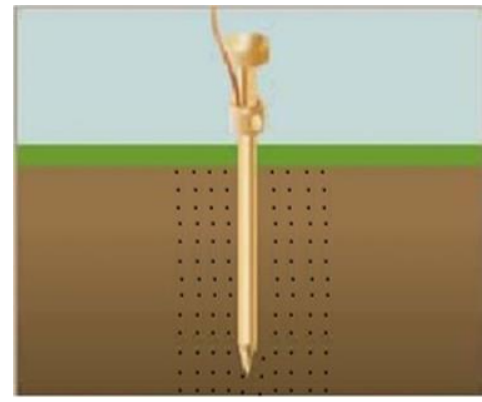

(a)

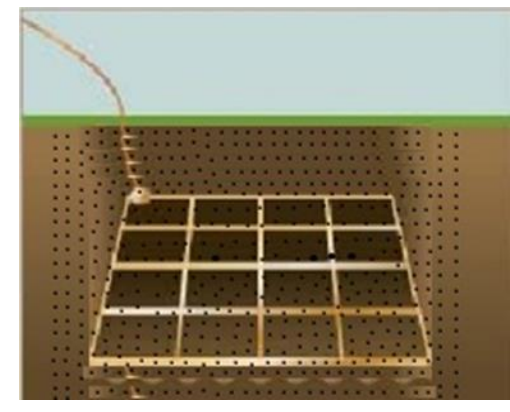

(b)

Figure 1. Nano-tech earthing systems for electrical power substations, (a) nano-tech electrodes grounding systems, (b) nano-tech grid grounding systems

\section{PROPOSED NANOMETRIC SOIL MEDIA}

Nanoparticles, and nanomaterials in general, have become one of the new active materials being put into soil earthing system formulation to make the more efficient Nano-Tech earthing system. There are many reasons why this is being done, with the most common being that some nanomaterials have extremely high electrically conductive properties that can be utilized in soil formulation [21, 22]. Here, the conductive nanoparticles display extraordinary guarantee as options in contrast to ordinary conductive materials. As of late, utilization of conductive nanomaterials, for example, conductive metal nanomaterials have opened new opportunities for electronic and optoelectronic devices. Besides, adding adaptability to conductive nanomaterials improves the application in the fields of wearable electronics, electromagnetic interference (EMI) shielding, and wearable antennas. Consequently, the conductive nanomaterials have been utilized as options for developing grounding systems in contrast to customary conductive metals of traditional grounding systems. The need of the conductive metal nanomaterials industry is finding the best technique for delivering practical, excellent conductive metal nanomaterials at a mechanical scale. Conductive nanoparticles offer several advantages in soil of Nano-Tech earting systems. Table 1 depicts nanoparticles types and specific soil resistance of the soil.

Table 1. Types of nanoparticles and soil resistivity of the soil [23-25]

\begin{tabular}{ccc}
\hline Materials & \multicolumn{2}{c}{ Specific Earth Resistance $\rho[\Omega . \mathrm{m}]$} \\
\hline Sandy Soil & 450 \\
& Nanoparticles & \\
Copper & & 1.694 \\
Aluminum & 2.67 \\
Iron & 10.1 \\
\hline
\end{tabular}

\section{RESULTS AND DISCUSSION}

This research is enhancing the traditional ground system performance in electrical power substation by using new Nano-Tech earthing system that provide earthing resistance equal to nano-Ohm order. Due to the importance of types and concentrations of nanoparticles in traditional grounding systems for electrical power substations, the following results are illustrated an efficient nanoparticles and concentrations for obtaining the best ground system performance.

\subsection{Effect of nanoparticles on electrode earthing systems}

Developing electrode earthing systems has shown in Figure 2, it obvious that performance of traditional electrode earthing system (0 \%wt. nanoparticles) as shown in Figure 2(a), whatever, the development of electrode earthing system has been depicted due to small penetration amount of conductive nanoparticles $(0.0 \%$ wt. up to $0.01 \%$ wt.) in sand soil as shown in Figure 2(b). It is obavious that the conduction of electrode ground systems decreases with increasing nanoparticles volume fractions. In addition, it has been cleared that the copper materials of electrodes and nanoparticles have an efficient conduction material with respect to aluminum and iron materials. Also, developing electrode earthing systems are shown in Figure 3, it obvious that performance of traditional electrode earthing system $(0.0 \%$ wt. nanoparticles). Distribution of nanoparticles (0.01\%wt.) inside sand soil tends to reduce electrode resistance then enhancing the conduction of Nano-Tech electrodes grounding systems. In addition, it has been cleared 
that the nanoparticles materials have an efficient factor for reduction the ground resistance with respect to length of electrodes materials. In case of using Nano-Tech electrodes grounding systems, it has been cleared that using copper nanoparticles as shown in Figure 3(a) provided more reduction in ground resistance for electrical substations that reach to nano-ohm with respect to traditional ground systems. On the other wise, Figure 3(b) shows the effect of Aluminum nanoparticles for enhancing grounding systems with variant nanoparticles concentrations, whatever, the effect of Iron nanoparticles on grounding systems have been shown in Figure 3(c).

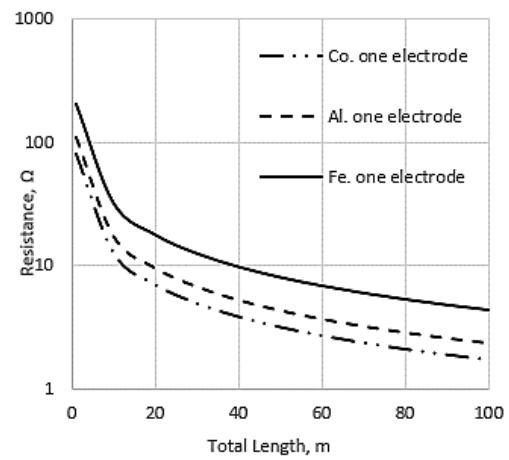

(a)

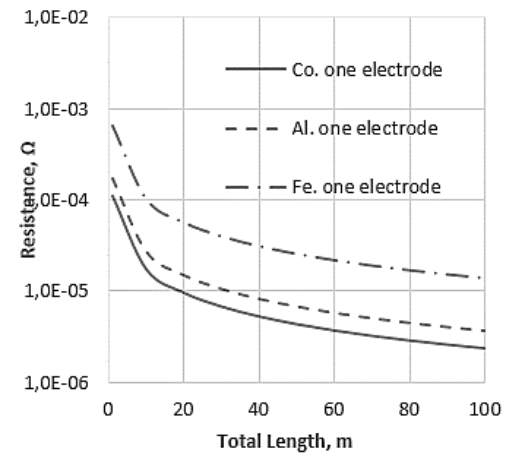

(b)

Figure 2. Modified electrode using sand nanoparticles by variations of number of electrodes, (a) $0.0 \%$ wt. nanoparticles+sand, (b) $0.01 \%$ wt. nanoparticles+sand

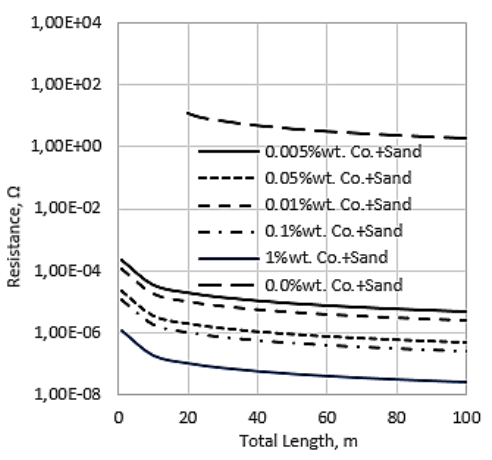

(a)

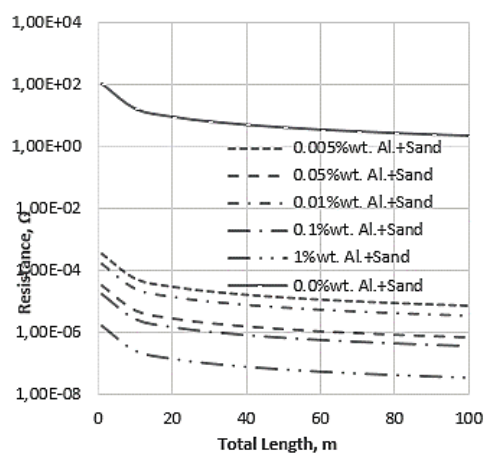

(b)

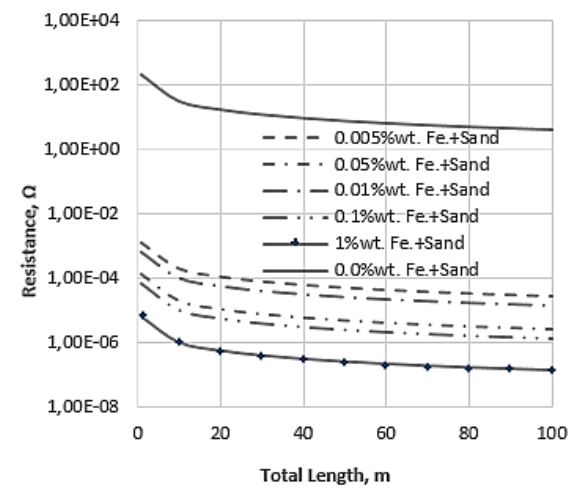

(c)

Figure 3. Modified electrode using sand nanoparticles by variations of volume fractions, (a) unique copper electrode, (b) unique aluminum electrode, (c) unique iron electrode 


\subsection{Effect of nanoparticles on grid earthing systems}

Figure 4 shows the developing of grid earthing systems and obvious that effect of nanoparticles on grid resistance and conduction of grid ground systems variant volume fractions. Figure 4(a) shows the effect of traditional grid earthing systems for natural sand soil (0.0\%wt nanoparticles). Whatever, Figure 4(b) shows that penetration of small amount of nanoparticles $(0.0001 \% \mathrm{wt}$.) in the sand soil earthing system to make a huge reduction of ground resistance of earthing system. It has been cleared that type of grid materials still more efficient for increasing conduction of ground system.

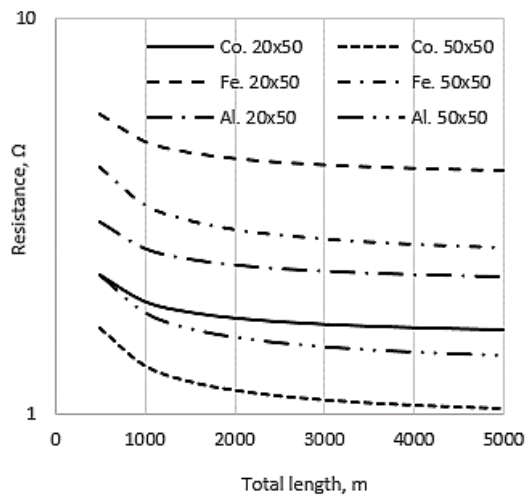

(a)

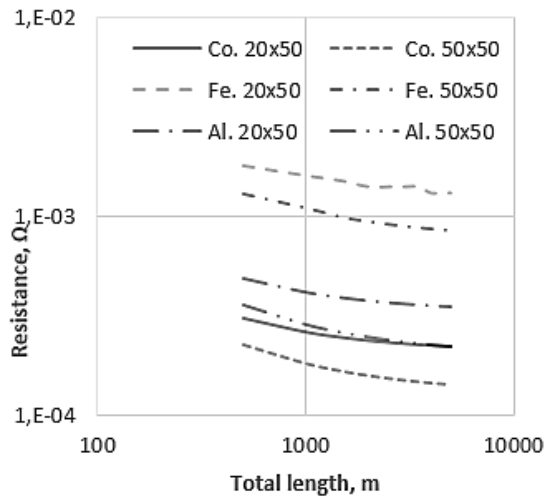

(b)

Figure 4. Modified grid using sand nanoparticles by variations of volume fractions, (a) $0.0 \%$ wt. nanoparticles+sand, (b) $0.0001 \%$ wt. nanoparticles+sand

\section{TREND OF NANOPARTICLES IN SOIL EARTHIG SYSTEMS}

Exact structure of the grounding system requires a precise evaluation of the site's soil conditions. In any case, even a little site will frequently have broadly fluctuating soil resistivity starting with one spot then onto the next. Soil resistivity is an element of a few factors, these variables incorporate the kind of soil, dampness content, temperature, mineral substance, granularity and conservatives. In convention earthing systems, dampness, minerals, and broke up salts are the main factors that can be impacted by any reasonable control idea. Information on the nearby soil conditions is compulsory and is the initial phase in the structure procedure. This incorporates its dampness substance, temperature, and resistivity under a given arrangement of conditions. Since about $94 \%$ of the grounding resistance of a given electrode is dictated by the character of the soil inside grounding system, with nanotechnology science, the penetration process of conductive nanoparticles inside grounding soil site is an efficient solution to get more conductive pass of excessive current pass in power station. In case of Nano-Tch ground system design, the ground resistance reached micro or nano ohm resistance that is investigated the stability and reliability of the electric power stations. A more practical action may be to replace only that part of the soil that exercises the greatest influence on the ultimate grounding resistance and to use the lowest resistivity "soil" available [23-25].

In Nano-Tech earthing system, Nanoparticles can be embedded in soil of earthing system and the structure of soil composite is random. It does not help to develop highly conductive particles for composites if they do not touch each other: The electrons have to tunnel through the gaps, and electric conductivity is improving control of the distribution of the particles inside the soil. Conductive nanoparticles (NPs) can increase the number of electroporated cells, they have a more pronounced impact on the soil electrification. Thus, it can be available to be controlled the soil resistivity by varying the structure of soil. Mixing conductive nanoparticles through soil of grounding site has been effective methodology for reducing soil resistivity and then make a lowest earthing resistance for electric power substations. Table 2 shows a comparative result between electrodes grounding systems in pure sand soil and Nano-Tech electrode earthing systems. It has been cleared that a small concentration $(0.005 \%$ wt. $)$ of conductive nanoparticles of the same electrode material helps to reduction earthing resistance to be micro-ohm. Moreover, Tables 3 and 4 show the

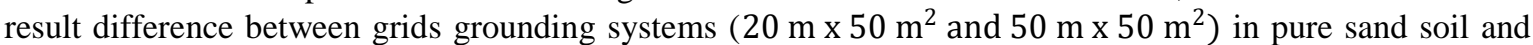
nano-tech electrode earthing systems. It has been cleared that a very small concentration (0.00001\%wt.) of conductive nanoparticles of the same grid material helps to reduction earthing resistance to be micro-ohm. 
Table 2. Traditional and nano-tech electrode earthing systems (copper, aluminum, iron)

\begin{tabular}{ccccccc}
\hline Length $(\mathrm{m})$ & \multicolumn{2}{c}{ 0 \%wt. nanoparticles+Sand } & \multicolumn{3}{c}{$0.005 \%$ wt. nanoparticles+Sand } \\
& Copper & Aluminum & Iron & Copper & Aluminum & Iron \\
\hline 1 & 79.82 & 108.69 & 201.91 & $2.20 \times 10^{-04}$ & $3.46 \times 10^{-04}$ & $1.31 \times 10^{-03}$ \\
10 & 12.49 & 17.01 & 31.60 & $3.44 \times 10^{-05}$ & $5.42 \times 10^{-05}$ & $2.05 \times 10^{-04}$ \\
20 & 6.93 & 9.43 & 17.52 & $1.91 \times 10^{-05}$ & $3.00 \times 10^{-05}$ & $1.14 \times 10^{-04}$ \\
30 & 4.88 & 6.65 & 12.35 & $1.34 \times 10^{-05}$ & $2.12 \times 10^{-05}$ & $8.01 \times 10^{-05}$ \\
40 & 3.80 & 5.18 & 9.62 & $1.05 \times 10^{-05}$ & $1.65 \times 10^{-05}$ & $6.24 \times 10^{-05}$ \\
50 & 3.13 & 4.26 & 7.91 & $8.61 \times 10^{-06}$ & $1.36 \times 10^{-5}$ & $5.14 \times 10^{-05}$ \\
60 & 2.67 & 3.63 & 6.75 & $7.34 \times 10^{-06}$ & $1.16 \times 10^{-05}$ & $4.38 \times 10^{-05}$ \\
70 & 2.33 & 3.17 & 5.89 & $6.41 \times 10^{-06}$ & $1.01 \times 10^{-05}$ & $3.82 \times 10^{-05}$ \\
80 & 2.07 & 2.82 & 5.24 & $5.70 \times 10^{-06}$ & $8.98 \times 10^{-06}$ & $3.40 \times 10^{-05}$ \\
90 & 1.87 & 2.54 & 4.72 & $5.14 \times 10^{-06}$ & $8.10 \times 10^{-06}$ & $3.06 \times 10^{-05}$ \\
100 & 1.70 & 2.32 & 4.30 & $4.68 \times 10^{-06}$ & $7.38 \times 10^{-06}$ & $2.79 \times 10^{-05}$ \\
\hline
\end{tabular}

Table 3. Traditional grid earthing systems (copper, aluminum, iron)

\begin{tabular}{|c|c|c|c|c|c|c|}
\hline \multirow[t]{3}{*}{ Length $(\mathrm{m})$} & \multicolumn{6}{|c|}{$0 \%$ wt. nanoparticles+Sand } \\
\hline & \multicolumn{2}{|c|}{ Copper $\left(\mathrm{m}^{2}\right)$} & \multicolumn{2}{|c|}{ Aluminum $\left(\mathrm{m}^{2}\right)$} & \multicolumn{2}{|c|}{$\operatorname{Iron}\left(\mathrm{m}^{2}\right)$} \\
\hline & $20 \times 50$ & $50 \times 50$ & $20 \times 50$ & $50 \times 50$ & $20 \times 50$ & $50 \times 50$ \\
\hline 500 & 2.2457 & 1.6487 & 3.0608 & 2.2471 & 5.7043 & 4.1879 \\
\hline 1000 & 1.9191 & 1.3221 & 2.6156 & 1.8020 & 4.8747 & 3.3583 \\
\hline 1500 & 1.8027 & 1.2057 & 2.4570 & 1.6433 & 4.5790 & 3.0626 \\
\hline 2000 & 1.7422 & 1.1452 & 2.3745 & 1.5608 & 4.4253 & 2.9089 \\
\hline 2500 & 1.7049 & 1.1079 & 2.3236 & 1.5100 & 4.3305 & 2.8141 \\
\hline 3000 & 1.6794 & 1.0824 & 2.2890 & 1.4753 & 4.2660 & 2.7495 \\
\hline 3500 & 1.6610 & 1.0640 & 2.2638 & 1.4501 & 4.2190 & 2.7026 \\
\hline 4000 & 1.6469 & 1.0499 & 2.2447 & 1.4310 & 4.1833 & 2.6669 \\
\hline 4500 & 1.6358 & 1.0389 & 2.2296 & 1.4159 & 4.1552 & 2.6388 \\
\hline 5000 & 1.6269 & 1.0299 & 2.2174 & 1.4037 & 4.1325 & 2.6160 \\
\hline
\end{tabular}

Table 4. Nano-Tech grid earthing systems (copper, aluminum, iron)

\begin{tabular}{ccccccc}
\hline Length $(\mathrm{m})$ & \multicolumn{5}{c}{ Copper $\left(\mathrm{m}^{2}\right)$} & \multicolumn{3}{c}{ 00001 \%wt. nanoparticles+Sand } \\
& $20 \times 50$ & $50 \times 50$ & $20 \times 50$ & $50 \times 50$ & $20 \times 50$ & $50 \times 50$ \\
\hline 500 & $3.10 \times 10^{-03}$ & $2.30 \times 10^{-03}$ & $4.80 \times 10^{-03}$ & $3.60 \times 10^{-03}$ & 0.0182 & $1.33 \times 10^{-02}$ \\
1000 & $2.60 \times 10^{-03}$ & $1.80 \times 10^{-03}$ & $4.10 \times 10^{-03}$ & $2.80 \times 10^{-03}$ & 0.0155 & $1.07 \times 10^{-02}$ \\
1500 & $2.50 \times 10^{-03}$ & $1.70 \times 10^{-03}$ & $3.90 \times 10^{-03}$ & $2.60 \times 10^{-03}$ & 0.0146 & $9.80 \times 10^{-03}$ \\
2000 & $2.40 \times 10^{-03}$ & $1.60 \times 10^{-03}$ & $3.80 \times 10^{-03}$ & $2.50 \times 10^{-03}$ & 0.0141 & $9.30 \times 10^{-03}$ \\
2500 & $2.30 \times 10^{-03}$ & $1.50 \times 10^{-03}$ & $3.70 \times 10^{-03}$ & $2.40 \times 10^{-03}$ & $1.38 \times 10^{-02}$ & $9.00 \times 10^{-03}$ \\
3000 & $2.30 \times 10^{-03}$ & $1.50 \times 10^{-03}$ & $3.60 \times 10^{-03}$ & $2.30 \times 10^{-03}$ & $1.36 \times 10^{-02}$ & $8.80 \times 10^{-03}$ \\
3500 & $2.30 \times 10^{-03}$ & $1.50 \times 10^{-03}$ & $3.50 \times 10^{-03}$ & $2.30 \times 10^{-03}$ & $1.34 \times 10^{-02}$ & $8.60 \times 10^{-03}$ \\
4000 & $2.30 \times 10^{-03}$ & $1.40 \times 10^{-03}$ & $3.50 \times 10^{-03}$ & $2.30 \times 10^{-03}$ & $1.33 \times 10^{-02}$ & $8.50 \times 10^{-03}$ \\
4500 & $2.30 \times 10^{-03}$ & $1.40 \times 10^{-03}$ & $3.50 \times 10^{-03}$ & $2.20 \times 10^{-03}$ & $1.32 \times 10^{-02}$ & $8.40 \times 10^{-03}$ \\
5000 & $2.30 \times 10^{-03}$ & $1.40 \times 10^{-03}$ & $3.50 \times 10^{-03}$ & $2.20 \times 10^{-03}$ & $1.32 \times 10^{-02}$ & $8.30 \times 10^{-03}$ \\
\hline
\end{tabular}

\section{CONCLUSION}

Nanoparticles distribution in the soil has been controlled in reduction of soil resistivity that has affected on grounding resistance of earthing system. Penetration of nanoparticles inside soil matrix is accepting changing the electrical properties of soil resistivity that has been increasing conductivity to flow the fault currents from the electric power system. A small concentration of conductive nanoparticles of the same electrode material helps to reduction the earthing resistance to be micro-ohm. Nano-Tech earthing methodology has been treated power substation soil with nanoparticles that has been deduced more efficient procedure for obtaining soil resistivity reduction with respect to traditional methodology. Nano-Tech earthing systems is more efficient for controlling in grounding system parameters of electrical substations with respect to type and concentration of inclusions because of the conductive nanoparticles increase the number of electroporated cells, they have a more pronounced impact on the soil electrification

\section{ACKNOWLEDGEMENTS}

The present work was supported by high voltage laboratory that has been established on 2016 and followed the Electrical Engineering Department, College of Engineering at Qassim University in Buraydah, KSA. 


\section{REFERENCES}

[1] A. Th. Mohamed, and O. E. Gouda, "Grounding Systems for Electric Substations in Non-Uniform Soil: Design and Operation," LAP LAMBERT Academic, 2014.

[2] Md. Abdus SALAM, Q. M. Rahman, S. P. ANG, and F. Wen, "Soil resistivity and ground resistance for dry and wet soil," Journal of Modern Power Systems and Clean Energy, vol. 5, pp. 290-297, 2017.

[3] O. E. Gouda, "Design Parameters of Electrical Network Grounding Systems," IGI Global Publisher, pp. 1-316, 2018.

[4] Ch. C. Tung, and S. C. Lim, "Performance of electrical grounding system in soil at low moisture content condition at various compression levels," Journal of Engineering Science and Technology, vol. 12, no. 1, pp. 27-47, 2017.

[5] M. Sh. Reffin, N. M. Nor, N. N. Ahmad and S. Abdullah, "Performance of Practical Grounding Systems under High Impulse Conditions," Energies, vol. 11, no. 11, pp. 3187, 2018.

[6] L. M. Popovic, "Practical Methods for Analysis and Design of HV Installation Grounding Systems," Paperback, 2018.

[7] A. Makkieh, A. Emhemed, D. Wang, A. Junyent-Ferre, and G. Burt, "Investigation of different system earthing schemes for protection of low-voltage DC microgrids," The Journal of Engineering, vol. 2019, no. 18, pp. 5129-5133, 2019.

[8] Q. Xu, J. He, S. Huang, J. Zeng, Ch. Fan, and W. Wang, "Researches on grounding modes of the AC/DC hybrid system with various distributed renewable energy," The Journal of Engineering, vol. 2019, no. 16, pp. 3035-3038, 2019.

[9] Ch. Zhao, L. Tang, D. Huang, J. Xia, X. Liu, and X. Xu, "Study on the scheme design of integrated grounding system for a $550 \mathrm{kV}$ gas insulated transmission line," The Journal of Engineering, vol. 2019, no. 16, pp. 2551- 2555, 2019.

[10] A. Sunjergaa, Q. Lia, D. Poljakc, M. Rubinsteind, and F. Rachidia, "Isolated vs. Interconnected Wind Turbine Grounding Systems: Effect on the Harmonic Grounding Impedance, Ground Potential Rise and Step Voltage," Electric Power Systems Research, vol. 173, pp. 230-239, 2019.

[11] L. K. Yuan Jet, N. E. Eng, and N. M. Nor, "Design of a Substation Grounding System for Fast Front Overvoltage," International Journal of Recent Technology and Engineering, vol .8, no. 3S, pp. 20-24, 2019.

[12] M. F. B. R. Gonçalvesa,c, E. G. da Costab, A. F. Andradea, V. S. Britod, G. R. S. Lirab, and G.V.R. Xavier, "Grounding system models for electric current impulse," Electric Power Systems Research, vol. 177, no. 105981, 2019.

[13] "IEEE Std 80-2013 (Revision of IEEE Std 80-2000/Incorporates IEEE Std 80-2013/Cor 1-2015)," IEEE Guide for Safety in AC Substation Grounding, 2013.

[14] A. Thabet, S. Abdelhady and Abdel-Moamen M. A., "Design of multi-nanoparticles technique for enhancing magnetic characterization of power transformers cores," Advances in Electrical and Electronic Engineering Journal, vol. 16, no. 2, pp. 167-177, 2018.

[15] A. Thabet, M. Samir, and Mountasser M. M. Mahmoud, "New Design for polypropylene thin film of HV metallized power capacitor using multiple nanoparticles technique," 2018 Twentieth International Middle East Power Systems Conference (MEPCON), Cairo, Egypt, 2018, pp. 122-127.

[16] A. Thabet, and Y. A. Mubarak "Thermal Experiment Analysis for Dielectric Characterization of High-Density Polyethylene Nanocomposites," Advances in Electrical and Electronic Engineering, vol. 14, no. 3, pp. 295-303, 2016.

[17] O. Gouda, and A. Thabet, "Experimental Verification on Enhancing Electric and Dielectric Phenomena of Transformer Nanofluids," Materials Research Proceedings vol. 1, pp. 243-246, 2016.

[18] A. Thabet, and Y. A. Mubarak "Experimental Enhancement for Electric Properties of Polyethylene Nanocomposites under Thermal Conditions," Advances in Electrical and Electronic Engineering, vol. 15, no. 1, pp. 55-62, 2017.

[19] A. Thabet," Theoretical Analysis for effects of nanoparticles on dielectric characterization of electrical industrial materials," Electrical Engineering, vol. 99, no. 2, pp. 487-493, 2017.

[20] A Thabet, and Y. A. Mubarak," The Effect of Cost-Fewer Nanoparticles on the Electrical Properties of Polyvinyl Chloride," Electrical Engineering, vol. 99, no. 2, pp. 625-631, 2017.

[21] S. Naghdi, K. Y. Rhee, D. Hui and S. Jin Park, "A Review of Conductive Metal Nanomaterials as Conductive, Transparent, and Flexible Coatings, Thin Films, and Conductive Fillers: Different Deposition Methods and Applications," Coatings, vol. 8, no. 8, pp. 1-27, 2018.

[22] Sh. Ahmad, K. Subhani, A. Rasheed, M. Ashraf, A. Afzal, B. Ramzan and Z. Sarwar, "Development of Conductive Fabrics by Using Silver Nanoparticles for Electronic Applications," Journal of Electronic Materials, vol. 49, pp. 1330-1337, 2020.

[23] Jr. R. B. Carpenter, and J. A. Lanzoni, "Designing for A Low Resistance Earth Interface (Grounding)," Lightning Eliminators and Consultants, Inc., pp. 1-16, 2007.

[24] A. L. Vikram, Vaghamshi, and K. A, Sonagra, "Substation Grounding Grid Design Case Study Using Matlab," in International Journal for Scientific Research and Development, vol. 2, no. 3, pp. 748-751, 2014.

[25] R. Shariatinasab, J. Gholinezhad, "The effect of grounding system modeling on lightning-related studies of transmission lines," Journal of Applied Research and Technology, vol. 15, no. 6, pp. 545-554, 2017. 